\title{
The effectiveness of inhaled corticosteroid therapy in preschool children with asthma: a systematic review of literature
}

\author{
Deborah Enting, Siebrig Schokker, Eric J Duiverman, Thys van der Molen
}

\begin{abstract}
Objective

To evaluate the effectiveness of inhaled corticosteroid therapy in asthmatic children in the age group of $0-6$ years.

\section{Study design}

Systematic review of randomised double blind placebo controlled trials of inhaled corticosteroid therapy for preschool children with asthma. 12 Trials were identified for this review. Data on symptom scores, parents' sleep disturbance, parents' assessment of asthma status/medication, concomitant drug use, exacerbation rate, lung function measurement, and adverse effects were retrieved form the trials.
\end{abstract}

\section{Results}

Most parallel trials showed significant improvements in symptom scores, concomitant drug use, exacerbation rate, or lung function measurements. Most improvements were seen in wheeze and concomitant drug use. The pooled odds ratio $(95 \%$ confidence interval (CI)) for outcome measure 'patients with at least one exacerbation' was 0.47 ( 0.3 to 0.73 ). Two crossover trials showed significant improvements in symptom scores, $\beta$-agonist use, and lung function. Significant differences in adverse effects between the active and placebo groups were not detected.

\section{Conclusion}

In conclusion, this systematic review of literature shows beneficial effects on symptoms, exacerbation rate, and pulmonary function for the use of inhaled corticosteroids in preschool children with asthma.

\section{Deborah Enting}

Department of General

Practice and Primary

Care, University of

Aberdeen

\section{Siebrig Schokker}

University of Groningen,

The Netherlands

\section{Eric J Duiverman}

University Hospital

Groningen, Netherlands

Thys van der Molen

University of Groningen,

The Netherlands

Correspondence to:

Miss Deborah Enting

Jacobstraat 3

9724 JN Groningen

The Netherlands

Tel: ++31503110717

Email:

d.enting@student.rug.nl

Prim Care Resp J 2003;

12(2):52-57

\section{Introduction}

Asthma is by far the most prevalent chronic disorder in childhood and is recognised as a major health problem in the Western World. ${ }^{1,2}$ Making the correct diagnosis of asthma in children is hampered by the heterogeneity of the symptoms. Asthma-like symptoms in the first years of life are very common. The prevalence rate of attacks of wheeze ever in preschool children was reported $29 \%$ in Leicestershire, United Kingdom. Cough apart from colds had a prevalence rate of $22 \%{ }^{3}$ Symptoms such as wheeze and cough often disappear when the child becomes older. This group of children is referred in literature as transient wheezers. These children have lower levels of lung function early in life and are therefore more likely to wheeze in association with a viral upper airway infection. ${ }^{4}$ However, there is a group of children who continue to have asthmatic symptoms after infancy. These children tend to have more chronic and severe symptoms, not only associated with a viral upper airway infection. This group is more likely to have atopic asthma. From a clinical viewpoint it is currently impossible to distinguish clearly between these two groups during the first few years of life since children are too young to perform reliable and clinically applicable lung function measurements while symptoms are often similar.

Inhaled corticosteroids are often used in children with asthma-like symptoms early in life. Calpin et al. conducted a systematic review on childhood asthma in the age group of 0-18 years receiving inhaled corticosteroids. ${ }^{5}$ They have found marked improvements in clinical and lung function in the inhaled steroid group compared with the placebo group in the majority of the studies. However, in this review trials have also been included in which inhaled corticosteroids are used as an intermittent treatment, suggesting the inclusion of children with transient and or intermittent wheeze, rather than asthma. The Cochrane collaboration performed a review on inhaled steroids for episodic viral wheeze in children. ${ }^{6}$ They concluded that there is no current evidence for use of maintenance low dose inhaled steroids in prevention and management of episodic mild viral induced wheeze. A systematic review or meta-analysis on the effectiveness of inhaled corticosteroids in young children with true asthma (06 years) has not been performed yet. The aim of the present review is to give a systematic overview of the effectiveness of inhaled corticosteroid treatment compared to placebo in children with asthma in the age group of 0-6 years old.

\section{Methods}

\section{Inclusion criteria}

For this review we have tried only to include randomised double blind controlled trials comparing inhaled corticosteroids with placebo in children with doctor diagnosed asthma in the age-group 0-6 years.

In order to avoid inclusion of virus-associated wheeze rather than asthma, trials were excluded if the inhaled steroid dosage regime was intermittent. Another exclusion criterion was continuous oral steroid use. A list of excluded trials can be requested from the first author.

\section{Identification of the trials}

A computer search of MEDLINE (1966-August 2001), EMBASE (1980-August 2001), CINAHL (1982-August 2001), and Cochrane databases was used. Medical subject headings included "asthma" and, "child preschool" or, "infant" and, "steroids" or, 
Table 1 Characteristics of studies included in review.

\begin{tabular}{|c|c|c|c|c|c|c|c|c|c|}
\hline study & design & $\begin{array}{c}\text { no of } \\
\text { participants }\end{array}$ & $\begin{array}{l}\text { age, mean } \\
\text { (mo) }\end{array}$ & $\begin{array}{l}\text { age, range } \\
\text { (mo) }\end{array}$ & $\begin{array}{c}\text { treatment } \\
\text { duration }(w k)\end{array}$ & drug & $\begin{array}{c}\text { dose/day } \\
\text { (mg) }\end{array}$ & $\begin{array}{l}\text { inhalation device } \\
\text { vali }\end{array}$ & $\begin{array}{r}\text { Jadad } \\
\text { y score }\end{array}$ \\
\hline Storr ${ }^{11}$ & parallel & 29 & 43.2 & $20-67.2$ & 24 & BDP & 0.3 & Nebulizer+fm & 3 \\
\hline Connett ${ }^{12}$ & parallel & 36 & 21.6 & $12-31.2$ & 24 & BUD & $0.2-0.4$ & PMDI+spacer+fm & 1 \\
\hline de $\mathrm{Blic}^{8}$ & parallel & 38 & 17 & $6-30$ & 12 & BUD & 2.0 & Nebulizer $+f m$ & 3 \\
\hline de Benedictis ${ }^{13}$ & parallel & 17 & 14.2 & $4-32$ & 12 & FL & $0.04 / \mathrm{kg}$ & Nebulizer+fm & 3 \\
\hline Bisgaard ${ }^{9}$ & parallel & 237 & 28 & $12-47$ & 12 & FP & 0.1 or 0.2 & $\mathrm{PMDI}+$ spacer+fm & 3 \\
\hline Nielsen ${ }^{10}$ & parallel & 38 & 53 & $35-71$ & 8 & BUD & 0.8 & PMDI+spacer + fm & 3 \\
\hline Chavasse $^{14}$ & parallel & 37 & 9.3 & $5.2-13.9$ & 12 & $\mathrm{FP}$ & 0.3 & PMDI+spacer+fm & 5 \\
\hline Webb $^{15}$ & crossover & 13 & 40.9 & $23.6-59.8$ & 16 & BDP & 0.15 & Nebulizer+fm & 3 \\
\hline Gleeson $^{16}$ & crossover & 28 & 51 & $26-71$ & 17 & BUD & 0.4 & PMDI+spacer & 3 \\
\hline Greenough $^{17}$ & crossover & 18 & 54 & $24-72$ & 17 & BUD & 0.4 & PMDI+spacer & 3 \\
\hline Van Bever ${ }^{18}$ & crossover & 23 & 10.4 & $3-17$ & 8 & BUD & 1.0 & Nebulizer $+\mathrm{fm}$ & 3 \\
\hline Noble $^{19}$ & crossover & 24 & 11 & $4-17$ & 12 & BUD & 0.3 & PMDI+spacer+fm & 1 \\
\hline
\end{tabular}

$\mathrm{BDP}=$ beclomethasone dipropionate. $\mathrm{BUD}=$ budesonide. $\mathrm{FL}=$ flunisolide. $\mathrm{FP}=$ fluticasone propionate. $\mathrm{PMDI}=$ pressurised metered dose inhaler. $\mathrm{fm}=$ facemask.

"glucocorticoids" or,

"administration, inhalation", with publication type "clinical trial", or "randomised controlled trial". Useful references from these articles and reviews on childhood asthma were also retrieved. Only English-language articles were collected.

\section{Study appraisal and data extraction}

The validity of the trials was scored on the Jadad validityscale. ${ }^{7}$ This scale assesses the randomisation, double blinding and reports of dropouts and withdrawals. Trials with a score lower than three points are regarded as having poor validity. However, trials with a score lower than three points were included in this review because of the small number of trials identified for the review. Data on the effectiveness of inhaled steroids on clinical outcome measures (symptoms such as wheeze, cough and breathlessness, concomitant bronchodilator or oral steroid use, and exacerbation rate), parents' sleep disturbance, parents' assessment of asthma status or study medication, lung function, and adverse effects were retrieved from the trials. Data extraction was based on reported summary statistics. There was not sufficient data available to carry out a formal meta-analysis. Furthermore, outcome measures and scales varied among the trial. Both trials with parallel and crossover

\section{Table 2. Definitions of asthma between studies that were included in the review.}

Author

Storr et $a l^{11}$

Connett et $a l^{12}$

de Blic et $a l^{8}$

de Benedictis et $a l^{13}$ children with asthma defined as recurrent wheezing and cough (at least three episodes confirmed by a paediatrician) and the need for treatment with bronchodilators or oral steroids, or both in the previous six months. These children had to have a total score of 12 or more during the two week run-in period (cough and wheeze were scored twice daily on a $0-3$ scale)

Bisgaard et al Children with asthma defined as recurrent wheeze or asthma symptoms (wheeze, cough, breathlessness) on at least seven days of the two week run-in period or had required salbutamol. These children were defined as having moderate asthma according to the asthma grading on intensity of symptoms and use of rescue medication

Nielson et $a l^{10}$ Children with a diagnosis of asthma made empirically on the basis of recurrent asthma symptoms, clinical improvement with regular inhaled corticosteroid therapy and relapse during interruption of treatment. These children had to have a minmium score of four on at least seven days of the two week run-in period (cough, wheeze and shortness of breath were scored once per day on a 0-3 scale). The authors concluded that these patients represented a group of children with moderate severe asthma based on the high percentage of days $(95 \%)$ and nights (78\%) with symptoms.

Chavasse et al. ${ }^{14}$ Children with persistent wheezing and an atopic tendency. The study inclusion criteria were: a documented history of persistent wheeze/cough (occurring on at least three days/nights per week for six weeks); or recurrent wheeze (occurring on at least three occasions over the previous six months, and a personal history of eczema or a first degree relative with a history of atopy.

Webb et al. ${ }^{15} \quad$ Children with a clinical diagnosis of moderately severe asthma defined as inadequately controlled asthma on regular nebulised sodium cromoglycate with nebulised bronchodilator as required.

Gleeson et al. ${ }^{16}$ Preschool children with poorly controlled asthma defined as at least one attack per month in each of the previous three months or symptoms on most days or both.

Greenough et al. ${ }^{17}$ Used children from the study by Gleeson et al. and therefore used the same inclusion criteria.

Van Bever et al. ${ }^{18}$ Severe asthmatic children defined as recurrent coughing and wheezing unresponsive to classical antiasthmatic drugs including nebulised $\beta$-agonists and ipratropium bromide.

Noble et al. ${ }^{19}$ included infants with chronic wheezing, who had a history of recurrent cough or wheeze, or both for greater than two months and for three or more days a week. The children were each heard to wheeze on at least one occasion by a doctor. 
For personal use only.

Not to be reproduced without the permission of the Primary Care Respiratory Journal

Table 3. Summary of results on symptoms in parallel trials. Results given as p-values, with significance level $=0.05$

\begin{tabular}{|c|c|c|c|c|c|c|c|c|c|c|}
\hline Study & \multicolumn{2}{|c|}{$\begin{array}{l}\text { total symptom } \\
\text { day score }\end{array}$} & \multicolumn{2}{|c|}{ total symptom wheeze } & $\begin{array}{c}\text { wheeze } \\
\text { night score }\end{array}$ & $\begin{array}{c}\text { cough } \\
\text { day score }\end{array}$ & $\begin{array}{c}\text { cough } \\
\text { night score }\end{array}$ & $\begin{array}{c}\text { SOB } \\
\text { day score }\end{array}$ & $\begin{array}{c}\text { SOB } \\
\text { night score }\end{array}$ & SFD \\
\hline Storr & & NA & NA & $<0.05$ & $<0.05$ & $>0.05$ & $>0.05$ & NA & NA & NA \\
\hline Connett & & NA & NA & $>0.05$ & $>0.05$ & $<0.03$ & $<0.05$ & NA & NA & NA \\
\hline de Blic & & NA & NA & $<0.05$ & $<0.01$ & $>0.05$ & $>0.05$ & NA & NA & NA \\
\hline de Benedi & ctis & NA & NA & $<0.05^{*}$ & $<0.05^{*}$ & $<0.05^{*}$ & $<0.05^{*}$ & NA & NA & NA \\
\hline Bisgaard & $\dagger$ & NA & NA & 0.039 & 0.074 & 0.101 & 0.31 & 0.827 & 0.053 & 0.71 \\
\hline & $t$ & NA & NA & 0.001 & 0.009 & 0.014 & 0.06 & 0.227 & 0.038 & 0.01 \\
\hline Nielsen & & 0.07 & 0.01 & 0.13 & 0.19 & 0.09 & 0.04 & 0.55 & 0.17 & 0.01 \\
\hline Chavasse & & $<0.05$ & $>0.05$ & $>0.05$ & $>0.05$ & $<0.05$ & $>0.05$ & NA & NA & $<0.05$ \\
\hline
\end{tabular}

$\mathrm{SOB}=$ shortness of breath. $\mathrm{SFD}=$ symptom free days. $\mathrm{NA}=$ this outcome measure was not assessed in this trial.

* daytime and night time symptoms not separated. $\dagger=100 \mu \mathrm{g}$ fluticasone propionate. $\$=100 \mu \mathrm{g}$ fluticasone propionate

Table 4 Summary of results on sleep disturbance, parents' assessment of child's asthma control, and rescue medication in parallel trials. Results given as p-values, with significance level $=0.05$

\begin{tabular}{|c|c|c|c|c|c|c|}
\hline \multirow[b]{2}{*}{ study } & \multicolumn{6}{|c|}{ rescue medication } \\
\hline & sleep disturbanc & $\mathrm{e}^{*}$ assessment parents & $\begin{array}{c}\beta \text {-agonist } \\
\text { day + night }\end{array}$ & $\begin{array}{c}\beta \text {-agonist } \\
\text { day }\end{array}$ & $\begin{array}{c}\beta \text {-agonist } \\
\text { night }\end{array}$ & oral steroid \\
\hline Storr & NA & NA & $<0.05$ & NA & NA & NA \\
\hline Connett & 0.07 & NA & NA & $>0.05$ & $<0.05$ & $>0.05$ \\
\hline de Blic & NA & $<0.005$ & 0.27 & NA & NA & $<0.05$ \\
\hline de Benedictis & NA & $>0.05$ & $>0.05$ & NA & NA & $>0.05$ \\
\hline Bisgaard $\ddagger$ & 0.002 & $>0.05$ & NA & 0.775 & 0.00 & 0.038 \\
\hline$\S$ & 0.041 & 0.06 & NA & 0.033 & 0.00 & 0.039 \\
\hline Nielsen & 0.06 & NA & NA & 0.01 & 0.09 & NA \\
\hline Chavasse & NA & NA & $>0.05$ & NA & NA & NA \\
\hline
\end{tabular}

*=sleep disturbance parents because of their child's asthma. $\uparrow=$ parents' assessment of child's asthma status/study medication. $\mathrm{NA}=$ this outcome measure was not assessed in this trial. $\$=100 \mu \mathrm{g}$ fluticasone propionate. $\S=100 \mu \mathrm{g}$ fluticasone propionate.

design were retrieved for this review. Parallel and crossover trials were analysed separately because of the risk of order and carry-over effects in the trials using a double blind crossover design.

\section{Statistical analysis}

The Mantel-Haenszel method was used to calculate odds ratio and $95 \%$ confidence interval $(\mathrm{CI})$ for proportion of patients with at least one exacerbation in three trials. ${ }^{8-10} \mathrm{~A} \Pi^{2}$-test was used to test homogeneity between trials, with a $\mathrm{p} \leq 0.05$ indicating significant heterogeneity. StatsDirect software was used to design the forest plot.

\section{Results}

A total of twelve trials have been identified for this review. Seven studies used a parallel design..$^{8-14}$ The other five studies used a crossover design. ${ }^{15-19}$

Characteristics of included trials are shown in table 1.

\section{Diagnosis of asthma}

In this review we tried to avoid inclusion of trials with children with transient wheeze. All studies aimed to focus on children with a clinical diagnosis of asthma. However, definitions of asthma differed between studies. The studies used the diagnosis of asthma based on symptoms or responsiveness, or both to medication (see table 2). As the authors mention, this group could not all necessarily be firmly classed as having asthma. The main question is whether these different definitions of asthma could have influenced our results.

Randomised double blind parallel placebo controlled trials

In total, 432 children with asthma were included in the analysis of the seven trials using a parallel design. The mean age of the participants was 23.4 months. The mean treatment duration was 15 weeks.

\section{Validity}

The major cause for subtracting points from the Jadad validity score was lack of well-described and appropriate randomisation

Table 3 and 4 show outcome measures and results on symptoms, parents' sleep disturbance, parents' assessment and rescue medication.

\section{Symptom diary cards}

All seven trials used daily diary cards to collect outcome measures on symptoms and concomitant drug use. Parents completed the diary cards. Three different scales were used to rate the symptoms, $0-3$ scale, ${ }^{9-11,13,14}$ $0-2$ scale $^{12}$ and yes $/$ no scale. ${ }^{8}$

\section{Wheeze and cough}

Wheeze and cough are the main symptoms retrieved from the diary cards with all seven trials reporting on these symptoms. One trial did not separate daytime and night time symptoms. ${ }^{13}$ Both wheeze and cough were significantly reduced in five studies, however, not in the same trials. On average, wheeze was reduced more often than cough as an outcome measure.

\section{Concomitant drug use - Bronchodilators}

All seven trials used frequency of bronchodilator use as an outcome measure. Various bronchodilators were used throughout the trials. When days and nights are pooled together, four out of eight trials were able to show a statistically significant improvement for bronchodilator usage in favour of the active treatment. ${ }^{9-12}$ 


\section{Exacerbations}

Five trials used exacerbation rate as an outcome measure. Various parameters were used, including proportion of patients with at least one exacerbation. ${ }^{8-10}$

We have calculated the number of patients with at least one exacerbation and without exacerbations in the two treatment groups, and used the data as a dichotomous outcome measure. Individual and pooled odds ratios $(95 \% \mathrm{CI})$ were calculated. A forest plot of individual odds ratios $(95 \% \mathrm{CI})$ and the pooled effect are shown in figure 1 . The pooled odds ratio $(95 \%$ CI) was 0.47 (0.3 to 0.73 ), suggesting a risk of $47 \%$ on at least one exacerbation for children using inhaled corticosteroids compared to children using placebo. Two other trials also used exacerbation rate as an outcome measure, however, they used different parameters than proportion of patients with at least one exacerbation, and therefore could not be included in the forest plot. Connett et al. used oral prednisolone in case of an acute exacerbation. ${ }^{12}$ They found no significant mean difference in dose prednisolone per patient between active treatment and placebo, suggesting no significant difference in exacerbation rate between the two groups. Chavasse et al. found no significant difference in number of exacerbation days between the two groups. ${ }^{14}$

\section{Lung function}

The trial by Nielsen et al. was the only parallel trial, which used lung function measurements as an outcome measure. Mean differences $(95 \% \mathrm{CI})$ between treatment groups and p-values are shown in table 5 .

\section{Adverse effects}

Six trials have paid attention to adverse effects. ${ }^{8}$, $11-14$ Oral candidiasis and eczematous rash in the face were most often reported, although the number of adverse effects did not differ significantly between active treatment and placebo. ${ }^{8,9,12,13}$ Other adverse effects, which occurred in small numbers, were throat irritation, dysphonia, cough, fever, gastritis, and diarrhea. ${ }^{9}$ Four of these seven trials reported data on patients' weight and/or height gain during the treatment period..$^{9,11,13,14}$ None of these trials showed a significant difference in height and/or weight between the active treatment and placebo groups.
Table 5 Summary of effects on lung function, in trial by Nielsen et al. ${ }^{11}$

Significance level $\alpha=0.05$

$\begin{array}{lccc}\text { variable } & \text { mean difference (BUD-placebo) } & \mathbf{9 5 \%} \text { CI } & \text { p-value } \\ \text { sRaw, } \mathrm{kPa}^{*} \mathrm{~s} & -0.07 & -0.25 \text { to } 0.11 & >0.05 \\ \mathrm{Rint}, \mathrm{kPa} \mathrm{s}^{*} \mathrm{~L}-1 & -0.15 & -0.03 \text { to }-0.27 & 0.01 \\ \mathrm{Xrs} 5, \mathrm{kPa}^{*} \mathrm{~s}^{*} \mathrm{~L}^{-1} & 0.13 & 0.05 \text { to } 0.21 & 0.001 \\ \mathrm{Rrs} 5, \mathrm{kPa}{ }^{\mathrm{s}} \mathrm{L}^{-1} & -0.18 & -0.060 \text { to }-0.30 & 0.01\end{array}$

BUD=budesonide. sRaw=specific airway resistance. Rint=resistance by interrupter technique. $\mathrm{Xrs} 5=$ airway reactance at $5 \mathrm{~Hz}$ by the impulse oscillation technique.

Rrs $5=$ airway resistance at $5 \mathrm{~Hz}$ by the impulse oscillation technique.

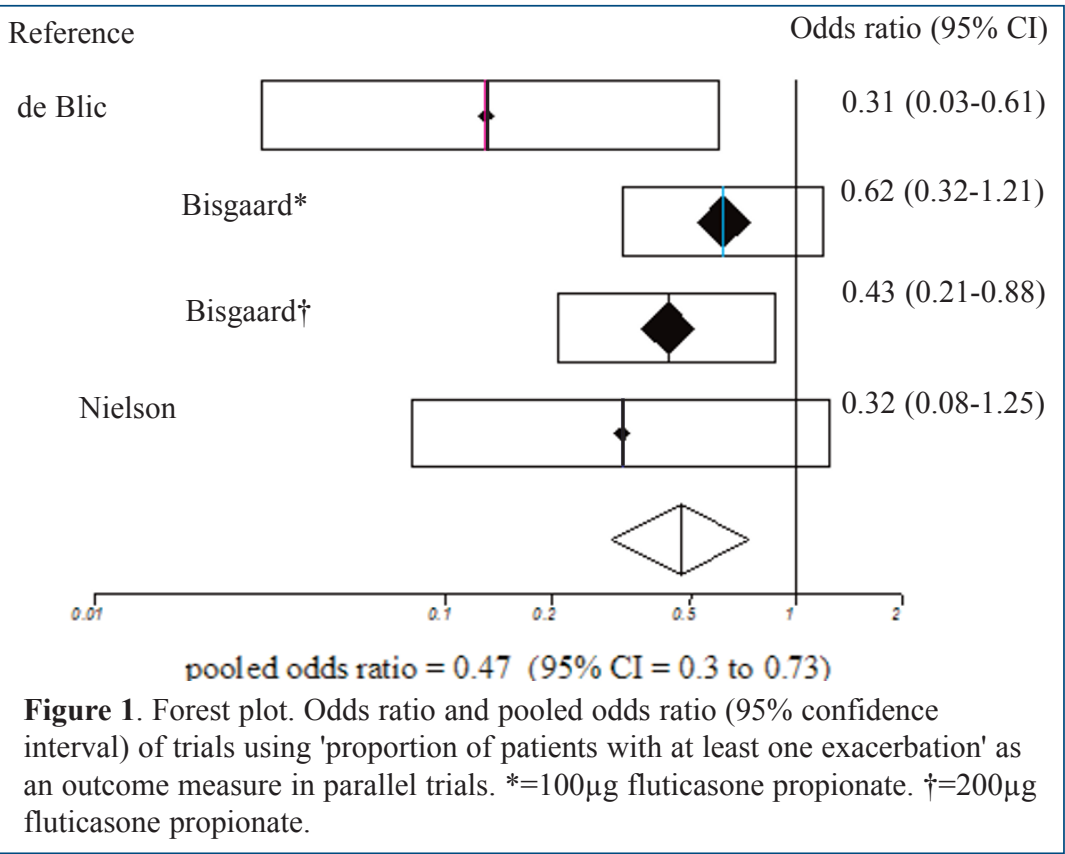

\section{Randomised double blind crossover placebo controlled trials}

In total, 106 children were analysed in five crossover trials. The mean age of the children was 32.4 months. The mean duration of treatment was 14 weeks.

\section{Validity}

The major cause for subtracting points from the quality score was the lack of well-described and appropriate randomisation.

Table 6. Summary of results on symptoms, assessment parents, rescue medication, and lung function in crossover trials. Results given as p-values, with significance level $\alpha=0.05$

\begin{tabular}{|c|c|c|c|c|c|c|c|c|c|c|c|c|c|}
\hline \multirow[b]{2}{*}{ Study } & & & & & & & & \multicolumn{6}{|c|}{ rescue medication lung function } \\
\hline & $\begin{array}{l}\text { total } \\
\text { symptom } \\
\text { score }\end{array}$ & $\begin{array}{c}\text { wheeze } \\
\text { day } \\
\text { score }\end{array}$ & $\begin{array}{c}\text { wheeze } \\
\text { night } \\
\text { score }\end{array}$ & $\begin{array}{l}\text { cough } \\
\text { day } \\
\text { score }\end{array}$ & $\begin{array}{l}\text { cough } \\
\text { night } \\
\text { score }\end{array}$ & $\begin{array}{c}\text { SOB } \\
\text { day } \\
\text { score }\end{array}$ & $\begin{array}{l}\text { SOB } \\
\text { night } \\
\text { score }\end{array}$ & SFD & $\begin{array}{c}\text { assessmen } \\
\text { parents* }\end{array}$ & $\begin{array}{l}\text { nt } \beta- \\
\text { agonist }\end{array}$ & $\begin{array}{c}\text { oral } \\
\text { t steroid }\end{array}$ & PEFR & FRC \\
\hline Webb & $>0.05$ & $>0.05 \dagger$ & $>0.05 \dagger$ & $>0.05 \dagger$ & $>0.05 \dagger$ & $>0.05 \dagger$ & $>0.05 \dagger$ & $>0.05$ & $>0.05$ & $>0.05$ & $>0.05$ & NA & NA \\
\hline Gleeson & NA & $>0.05$ & $<0.01$ & $>0.05$ & $<0.01$ & $>0.05 \dagger$ & $>0.05 \dagger$ & NA & NA & $<0.05$ & NA & $<0.05$ & NA \\
\hline Greenough & NA & NA & NA & NA & NA & NA & NA & NA & NA & NA & NA & NA & $>0.05$ \\
\hline Van Bever & $>0.05$ & $0.185 \dagger$ & $0.185 \dagger$ & $0.95 \dagger$ & $0.95 \dagger$ & $0.83 \dagger$ & $0.83 \dagger$ & NA & $>0.05$ & 0.226 & NA & NA & NA \\
\hline Noble & 0.03 & 0.03 & 0.13 & 0.04 & 0.07 & 0.02 & 0.02 & NA & $<0.05$ & 0.12 & NA & NA & IV \\
\hline
\end{tabular}

$\mathrm{SOB}=$ shortness of breath. $\mathrm{SFD}=$ symptom free days. *= parents' assessment of child's asthma status/study medication. $\dagger=$ daytime and night time symptoms not separated. $\mathrm{NA}=$ this outcome measure was not assessed in this trial. 


\section{Washout periods}

Four of the five crossover studies have used a washout period to minimise the risk of a carry over and order effect. ${ }^{16-19}$ The washout periods lasted for two to three weeks.

Table 6 shows outcome measures and results on symptoms, parents' assessment, rescue medication, and lung function.

\section{Symptom diary cards}

Four out of five trials supplied information on symptoms scores retrieved from daily diary cards completed by the parents. ${ }^{15,16,18,19}$ Parents rated the symptoms on a $0-3$ scale in these trials.

\section{Wheeze, cough and breathlessness}

Wheeze, cough and shortness of breath were the main symptoms retrieved from the diary cards, with four of the five trials reporting on these outcome measures. Two trials showed significant improvements in these symptoms in favour of the active treatment group. ${ }^{17,19}$

\section{Concomitant drug use - Bronchodilators}

Four out of five trials used frequency of bronchodilator use as an outcome measure. Various bronchodilators were used throughout the different trials. One trial showed a statistically significant difference between bronchodilator usage in favour the active treatment. ${ }^{16}$ The mean difference (95\% CI) between treatment groups in mean daily score for bronchodilator treatment was 0.52 (0.09 to 0.95$)$, $\mathrm{p}<0.05$.

\section{Adverse effects}

Three out of five studies provided data on adverse effects. ${ }^{15,16,18}$ Webb et al. paid attention to adverse effects though did not detect clinical side effects. No significant differences were found between the two groups in early morning plasma cortisol concentrations and eosinophil or neutrophil counts at the end of six weeks of treatment. ${ }^{16}$ Van Bever et al. did not find a significant difference between the treatments groups for oral candidiasis. An adrenocorticotrophic hormone test was performed twice in seven patients and showed no significant difference between the groups. Weight gain in the participants was also measured. There was no significant difference in weight gain between active treatment and placebo. ${ }^{18}$

\section{Discussion}

This is the first systematic review on the effectiveness of inhaled corticosteroids in preschool children with asthma.

In total twelve trials have been identified for in this literature review, including trials with parallel and crossover design. There is evidence that a crossover study may not have the appropriate design for comparing inhaled steroids with placebo. De Blic et al. showed in their parallel study on inhaled steroids that the difference between the two groups (inhaled steroids and placebo) occurred after one month and was maintained for the active group during several weeks of the follow-up period. ${ }^{8}$ Studies performed in older asthmatics have also shown this prolonged effect of inhaled steroids. ${ }^{2021}$ Since the washout periods used in these trials are moderately short, there is a chance that the results of these trials are confounded by a carry over effect.

The seven parallel trials showed statistically significant improvements in symptom scores, concomitant drug use, exacerbation rate and lung function. On average, wheeze was reduced more often than cough as a subjective outcome measure.

As mentioned previously, diagnosing asthma in young children is a difficult task. We have tried to include only patients who are likely to have asthma, and excluded patients with virus-associated wheeze. However, without data on long-term follow up of the children in these studies, we are not able to state that the children we have included have 'true' asthma (high risk of progressing asthma).

Another limitation of these trials is the use of different outcome measures. Subjective variables such as symptoms were measured in different ways. Most trials measured children's symptoms with daily diary cards completed by the parents, which depends on parents' ability to recognise symptoms and record their frequency. The majority of the trials used a 0-3 scale or even yes/no, which could have been too limited to be sufficiently responsive. A validated objective outcome parameter is also lacking. Only one parallel and two crossover trials used lung function or peak expiratory flow as objective measurements as outcome measure. ${ }^{10,16,17}$

The trial performed by Gleeson et al. showed a significant increase in peak expiratory flow. ${ }^{16}$ They used peak flow diaries to monitor the peak expiratory flow rate (PEFR). However, the reliability of these home recorded peak flow measurements in this age group is doubtful. Kamps et al. compared PEFR values in written diaries with peak flow values recorded on a microchip in children with asthma aged 5 to 16 years. They showed that the accuracy of the peak flow diaries even in these children was poor. ${ }^{22}$ Thankfully, developments in techniques for infant respiratory function testing are promising. ${ }^{23} 24$

There is concern that inhaled corticosteroids may reduce growth in children. Five trials included in this review have measured height and weight during treatment period. . $^{9} 11,13,14,18$ None of these trials showed significant differences in weight or height between the active and placebo treatment groups. However, it should be mentioned that the treatment duration of the trials was fairly short, with a mean of only 14 weeks. Also, the dose and delivery method of the drugs used could have played an important role in these trials. The doses of inhaled corticosteroids used were comparable with the recommended doses stated in the asthma guidelines by the British Thoracic Society. ${ }^{25}$ Hence, we do not assume that the variability in results could be due to the use of too low doses inhaled corticosteroids. 
However, the optimal use of an appropriate inhalation device is of major importance for adequate drug delivery into the intrapulmonary airways. Children in this age group ( $0-6$ years) rely on their parents for a correct inhalation technique. Even when the accurate inhalation technique is used, only a small percentage of the drug will reach the intrapulmonary airways. ${ }^{26}$ Lødrup Carlsen and colleagues showed a pulmonary deposition of less than $20 \%$ of the nominal dose of nebulised budesonide in infants and toddlers. The actual dose delivered to the children will vary between and within children.

In conclusion, this systematic review of literature shows beneficial effects on symptoms, exacerbation rate, and lung function for maintenance use of inhaled corticosteroids in preschool children with asthma.

\section{References}

1. Godfrey S. Childhood Asthma. In: Clark TJH, Godfrey S, Lee TH, Thomson NC, editors. Asthma. 4th ed. London: Arnold, 2000:381-425.

2. The International Study of Asthma and Allergies in Childhood (ISAAC) Steering Committee. Worldwide variations in the prevalence of asthma symptoms: the International Study of asthma and Allergies in Childhood (ISAAC). Eur Respir J 1998;12:315-35. 3. Kuehni CE, Davis A, Brooke AM, Silverman M. Are all wheezing disorders in very young (preschool) children increasing in prevalence? Lancet 2001;357:1821-5.

4. Martinez FD, Wright AL, Taussig LM, et al. Asthma and wheezing in the first six years of life. $N$ Eng J Med 1995;332:133-8.

5. Calpin C, Macarthur C, Stephens D, et al. Effectiveness of prophylactic inhaled steroids in childhood asthma: a systematic review of literature. $J$ Allergy Clin Immunol 1997;100;452-7.

6. McKean M, Ducharme F. Inhaled steroids for episodic viral wheeze of childhood (Cochrane review). In: Cochrane Collaboration. Cochrane Library. Issue 4. Oxford: Update software, 2001.

7. Jadad AR. Randomised controlled trials: a users' guide. 1st ed. BMJ Books; 1998.

8. de Blic J, Delacourt C, Le Bourgeois M, et al. Efficacy of nebulized budesonide in treatment of severe infantile asthma: a double-blind study. J Allergy Clin Immunol 1996;98:14-20.

9. Bisgaard H, Gillies J, Groenewald M, Maden C on behalf of an International Study Group. The effect of inhaled fluticasone propionate in the treatment of young asthmatic children: a dose comparison study. Am J Respir Crit Care Med 1999;160:126-31. 10. Nielsen KG, Bisgaard $H$. The effect of inhaled budesonide on symptoms, lung function, and cold air and methacholine responsiveness in 2- to 5-year-old asthmatic children. Am J Respir Crit Care Med 2000;162:1500-6.
11. Storr J, Lenney CA, Lenney W. Nebulised beclomethasone dipropionate in preschool asthma. Arch Dis Child 1986;61:270-3.

12. Connett GJ, Warde C, Wooler E, Lenney W. Use of budesonide in severe asthmatics aged 1-3 years. Arch Dis Child 1993;69:351-5.

13. de Benedictis FM, Martinati LC, Solinas LF, et al. Nebulized flunisolide in infant and young children with asthma: a pilot study. Pediatr Pulmonol 1996;21:310-5.

14. Chavasse RJ, Bastian-Lee Y, Richter H, et al. Persistent wheezing in infants with an atopic tendency responds to inhaled fluticasone. Arch Dis Child 2001;85:143-8.

15. Webb MSC, Milner AD, Hiller EJ, Henry RL. Nebulised beclomethasone dipropionate suspension. Arch Dis Child 1986;61:1108-10.

16. Gleeson JGA, Price JF. Controlled trial of budesonide given by the nebuhaler in preschool children with asthma. BMJ 1988;297:163-6.

17. Greenough A, Pool J, Gleeson JGA, Price JF. Effect of budesonide on pulmonary hyperinflation in young asthmatic children. Thorax 1988;43:937-8. 18. Van Bever HP, Schuddinck L, Wojciechowski M, Stevens WJ. Aerolized budesonide in asthmatic infants: a double blind study. Pediatr Pulmonol 1990;9:177-80.

19. Noble V, Ruggins NR, Everard ML, Milner AD. Inhaled budesonide for chronic wheezing under 18 months of age. Arch Dis Child 1992;67:285-8. 20. Juniper EF, Kline PA, Vanzieleghem MA, Hargreave FE. Reduction of budesonide after a year of increased use: a randomized controlled trial to evaluate whether improvements in airway responsiveness and clinical asthma are maintained. $J$ Allergy Clin Immunol 1991;82:483-9.

21. Haahtela T, Jarvinen M, Kava T, et al. Effects of reducing or discontinuing inhaled budesonide in patients with mild asthma. $N$ Eng $J$ Med 1994;331:700-5.

22. Kamps AWA, Roorda RJ, Brand PLP. Peak flow diaries in childhood asthma are unreliable. Thorax 2001;56:180-2.

23. Gappa M, Cloin AA, Goetz I, Stocks J. Passive respiratory mechanisms: the occlusion technique. Eur Respir J 2001;17:141-8.

24. McKenzie SA, Bridge PD, Healy MJ. Airway resistance and atopy in preschool children with wheeze and cough. Eur Respir J 2000; 15(5):833-8. 25. British Asthma Guidelines coordinating committee. The British guidelines on asthma management 1995 review and position statement. Thorax 1997;52 Suppl 1:1-21.

26. Lødrup Carlsen KC, Nikander K, Carlsen KH. How much nebulised budesonide reaches infants and toddlers? Arch Dis Child 1992;67:1077-9. 